\title{
DO CAMPO DE BATALHA À BATALHA IDEOLÓGICA: A HISTÓRIA DE UM FOREIGN FIGHTER QUE HOJE PREVINE A RADICALIZAÇÃO
}

\section{FROM THE BATTLEFIELD TO THE IDEOLOGICAL WAR: THE STORY OF A FOREIGN FIGHTER WHO NOWADAYS PREVENTS RADICALISATION}

\author{
Beatriz Buarque ${ }^{1}$
}

Desde 2014, o tema radicalização passou a ser recorrente não só no âmbito acadêmico, mas também na mídia. De repente surgiram vários especialistas no assunto, com explicações variadas para o processo (Borum, 2013) pelo qual mais de 20,000 jovens de mais de 90 países deixaram suas casas e se juntaram a grupos extremistas na Síria e Iraque (Neumann, 2016). A todo momento surgiram relatos de famílias de jovens canadenses, australianos, ingleses que teriam se radicalizado.

No entanto, os chamados foreign fighters não são uma criação da sociedade contemporânea. Na década de 80 , milhares de jovens do mundo todo se uniram aos mujahideen no Afeganistão, que estavam combatendo o exercito soviético com apoio da inteligência americana (Kepel, 2011). Em verdade, muitos pesquisadores acreditam que as raízes do jihadismo contemporâneo surgiram durante esse conflito, que possibilitou uma troca de ideologias extremistas oriundas de diferentes países. Para Wiktorowicz (2011), o conflito Afeganistão-URSS possibilitou um processo de radicalização que, posteriormente, culminou com o surgimento da Al-Qaeda - o primeiro grupo jihadista de alcance transnacional.

Portanto, radicalização entendida como o "processo de desenvolvimento de ideologias e crenças extremistas" (Borum, 2013: 9) também não é um fenômeno novo e indivíduos envolvidos no conflito no Afeganistão podem desempenhar um papel relevante no combate ao extremismo no cenário atual na medida em que conhecem a narrativa utilizada por grupos jihadistas e suas estratégias. É nesse contexto que eu conheci o paquistanês Shahid Butt. ${ }^{2}$

Com uma voz imponente, ele logo se destacou entre os convidados pela UNA-Coventry $^{3}$ em um debate sobre a política de combate ao extremismo e radicalização adotada

\footnotetext{
${ }^{1}$ Fundadora do portal de combate ao extremismo e radicalização Words Heal the Wold. Jornalista formada pela UFRJ. Atualmente está cursando mestrado em Relações Internacionais e Segurança no Reino Unido (University of Westminster). Pesquisadora interessada em temas ligados a terrorismo, propaganda extremista online, radicalização, discursos contra extremismo e engajamento com jovens. ORCID ID: https://orcid. org/0000-0003-1947-4946. Link para o Currículo Lattes: http://lattes.cnpq.br/7688529098996190. Contato: beatriz@wordshealtheworld.com.

${ }^{2}$ Uma versão completa da entrevista estará disponível a partir de 1 de Agosto 2018 no canal Words Heal the World no You Tube: https://www.youtube.com/channel/UC-2bZnFCazUYlzRZgbwR2XQ

${ }^{3}$ UNA-Coventry: afiliada da Associação das Nações Unidas em Coventry.

PREVENT é o programa de prevenção à radicalização implementado no Reino Unido em 2007.
} 
no Reino Unido. Ao ser chamado de "ex-terrorista" pelo organizador do evento, Shahid fez questão de deixar clara sua posição: "não sou terrorista. Não matei nenhum inocente". Desde 2016, Shahid vem trabalhando com comunidades muçulmanas para evitar que mais jovens sejam persuadidos pela ideologia pregada pelo ISIS. Para ele, a maioria dos jovens que são cooptados pelo grupo tem pouco conhecimento sobre o Islã:

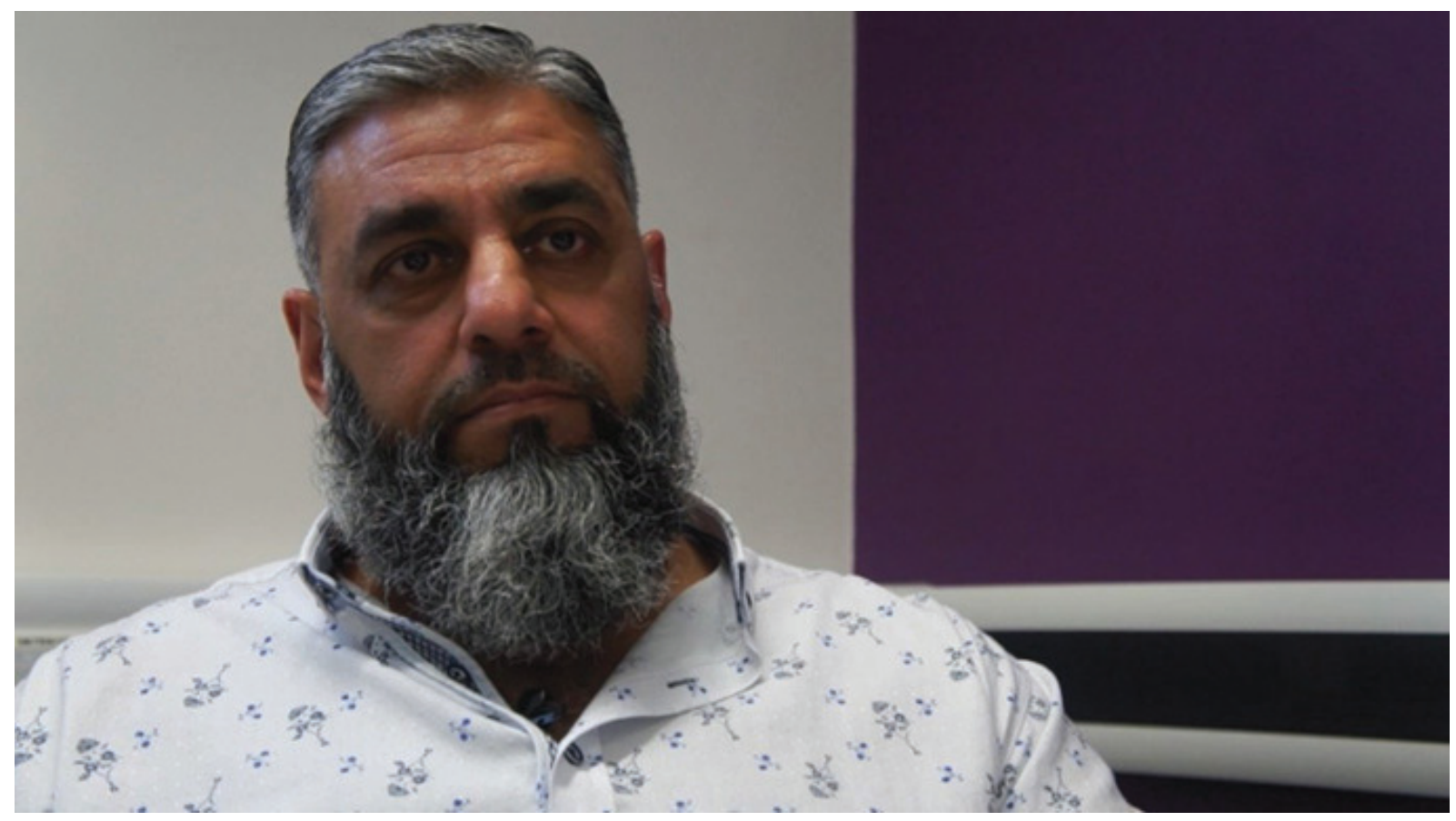

Foto: arquivo pessoal. Retrato tirado durante entrevista concedida à autora em 19/04/2018 - Birmingham, UK.

\section{Shahid}

"Quando você analisa, muitas dessas pessoas que estão envolvidas nesse tipo de coisa, a maioria delas são homens jovens. E quando você vai mais fundo, qual é o entendimento islâmico, para alguns deles é zero. Para alguns deles, é uma quantidade mínima de compreensão. E porque eles têm uma compreensão muito baixa da religião, eles são tão facilmente corrompidos. Se um recrutador do ISIS estiver conversando com alguém que não tenha conhecimento sobre o Islã e a pessoa disser que não há problema em matar pessoas inocentes, essa pessoa não sabe se isso é verdadeiro ou falso. Mas se uma pessoa tem uma compreensão básica da religião, ela sabe que no Alcorão Allá diz que se você mata uma pessoa, é como se você matasse toda a humanidade. Então, como pode ser aceitável matar uma pessoa inocente? “

Como estou à frente de um trabalho pioneiro de combate ao extremismo dentro da universidade, decidi entrevistar Shahid para entender melhor as motivações que levam uma pessoa a se juntar a um grupo extremista. Afinal, Shahid cresceu no Reino Unido, se uniu aos mujahideen na Bósnia, depois foi para o Afeganistão, Caxemira e lêmen, onde foi preso. Ele vivenciou a mistura das ideologias pregadas por Qutb e Al-Wahhab (Esposito, 2002), tidas como precursoras da ideologia disseminada pela Al-Qaeda, e posteriormente ainda mais polarizada pelo autoproclamado Estado islâmico. Para ele, o conceito de extremismo é controverso: 


\section{Shahid}

"Quando usamos essa palavra ideologia extremista e visões extremistas, o que você considera extremo, posso não considerar isso extremo. Alguém que vai lutar na Bósnia hoje seria considerado algo extremo. Mas para mim, não vejo isso como extremo. Eu considero isso como compaixão: por que uma pessoa não iria ajudar outra pessoa?"

Shahid explica que o que o motivou a ir para a Bósnia foi exatamente compaixão, já que num primeiro momento ele foi para lá oferecer ajuda humanitária à comunidade muçulmana.

\section{Shahid}

“Em 1991 ou 1992, recebi um videocassete chamado Massacres na Bósnia e na Croácia. $\mathrm{O}$ que eu vi naquele vídeo foi algo que eu não pude compreender em minha mente. $\mathrm{E}$ eu ainda me lembro do que eu pensava porque estava ligado ao meu cérebro e eu nunca vou esquecer isso. Lembro-me de perguntar a mim mesmo como pode um ser humano ser tão bárbaro com outro ser humano? Eu simplesmente não consegui entender"

\section{Beatriz}

Como você conseguiu o vídeo?

\section{Shahid}

"Alguém foi para a Bósnia e fez um documentário sobre o que estava acontecendo lá e estava distribuindo videocassetes grátis. Este vídeo foi muito horrível. Eu simplesmente não conseguia entender. Por que uma pessoa cortaria a barriga de uma grávida? Eu não entendo a lógica. Você é um ser humano? Você é uma pessoa má e bárbara? Havia cristãos envolvidos. Que tipo de pessoa religiosa é você? Eu senti que tinha que fazer alguma coisa. Então, eu sabia que havia um comboio saindo de Birmingham que estava indo para a Bósnia. Falei com o organizador "posso ir com você? " E ele disse "sim, não há problema". Então, isso é 1992. Chegamos a uma cidade chamada Travnik, na Bósnia, fomos encaminhados para uma escola, que foi convertida em um centro de refugiados e nos deram um quarto, colocaram uma mesa perto da porta e, então, eles chamaram todas as mães com seus filhos. Elas se alinharam do lado de fora. Recebi a incumbência de entregar os pacotes de comida. Então, vinha uma mãe com o filho, eu dava a comida. Então, eu fiz isso. Nós demos toda a ajuda que nós tínhamos. Fiquei muito satisfeito comigo mesmo, fiquei muito feliz"

Depois de explicar como chegou à Bósnia, Shahid descreveu sua infância violenta - o que, de acordo com ele, foi determinante para que ele se unisse aos mujahideen na Bósnia.

\section{Shahid}

"Meus anos de adolescência foram em gangues, lutando com skinheads, Frente Nacional, essas organizações racistas. Por tudo isso, passei mais tempo nas ruas do que na escola. Como consequência, minha educação sofreu na medida em que fui expulso da escola, então eu não fiz nenhuma prova ou algo assim. Quando eu era menino, lembro que, por um curto período de tempo, eu realmente tinha um complexo. Eu realmente pensei 
que havia algo errado com a cor da minha pele porque eu estava constantemente ouvindo "você não é aceito, saia"

Ao se ver sem dinheiro nem comida para doar às mães na Bósnia, Shahid diz que decidiu lutar pela comunidade muçulmana. Foi assim que começou sua longa jornada como efetivamente foreign fighter.

\section{Shahid}

"Eu me juntei à brigada de combatentes estrangeiros na Bósnia, a divisão mujahideen e lutei com os combatentes estrangeiros contra os sérvios na Bósnia. Eu estive lá por vários anos. Eu costumava ir e vir. Quando voltei, costumava recrutar outras pessoas, levá-las para a Bósnia, eu costumava fazer muitas palestras pelo país, destacando a questão sobre o que estava acontecendo na Bósnia, eu dava ajuda e então me juntei aos combatentes na linha de frente. Entre 1992 e 1998, também viajei ao Afeganistão para treinamento militar e também fui para Caxemira. Em 1998, fui preso no Iêmen. Fomos acusados falsamente de planejar ataques terroristas. Fui levado para um porão subterrâneo e fui torturado pela polícia. Eu fui forçado a assinar uma confissão, dizendo que estava planejando esses atos. No final do dia, fomos torturados, e você sabe, mesmo que você não tenha feito isso, você diz 'eu fiz isso'. Então, eu acabei dizendo 'sim'. Apenas me diga onde eu preciso assinar. Eu vou te admitir tudo"

Quando perguntei sobre as pessoas que ele conheceu no Afeganistão, Shahid confirmou a tese defendida por Wiktorowicz (2011) de que a presença de milhares de foreign fighters de diferentes países, com influências diversas, constituiu terreno fértil para o surgimento de uma nova ideologia radical: o jihadismo global (Hegghammer, 2006).

\section{Shahid}

"Eu conheci todos os tipos de pessoas durante meu tempo no Afeganistão. O mundo inteiro estava lá. Todo o mundo muçulmano estava lá. Conheci dezenas e dezenas de nacionalidades, conheci muitos grupos diferentes, organizações diferentes. 0 Afeganistão parecia um caldeirão. Você interagia com todas essas pessoas, mas não quer dizer que você fazia parte de um grupo específico. 0 grupo que eu estava era formado por paquistaneses e eles tinham seus próprios campos. Eles estavam muito focados na questão da Caxemira. Sim, havia outros grupos lá que também tinham uma visão jihadista internacional, grupos como - bem, não era a Al-Qaeda naquela época, mas pessoas desse grupo, sim. Eu estava em torno dessas pessoas, estava conversando com aquelas pessoas. E algumas dessas coisas influenciaram minha maneira de pensar"

Para Shahid, grupos jihadistas como Al-Qaeda e ISIS não surgem ao acaso. Ele acredita que a existência desses grupos está ligada aos interesses de algumas potências ocidentais.

\section{Shahid}

"Na minha opinião, e no meu entendimento, o ISIS é uma construção do ocidente, por certas potências ocidentais para servir a um determinado propósito. Olha, vamos voltar um pouco no tempo. Vamos voltar cinco, seis anos antes da criação do ISIS, quem era a ameaça do momento? Al-Qaeda. Você ainda ouve a palavra Al-Qaeda hoje em dia? Não. Por 
quê? Todas as pessoas da Al-Qaeda foram ao Havaí para passar as férias? Eles foram para a Disneylândia? 0 que aconteceu? Agora, quem é o novo? ISIS. Oh, meu Deus, o ISIS está chegando, o ISIS está chegando... Da mesma forma que a ameaça da Al-Qaeda, de repente, desapareceu, isso vai acontecer com o ISIS porque a mídia e os governos ocidentais estão controlando os extremos de todas essas pessoas, suas corporações, suas instituições. Eles estão todos envolvidos nisso e quando não servirem mais ao seu propósito, eles sairão de cena. Assim como o que aconteceu com a Al-Qaeda"

Apesar do ponto de vista empírico e teórico faltar evidências que comprovem a hipótese levantada por Shahid, para Wilkinson (2001), grupos jihadistas e a mídia convivem em uma relação quase simbiótica na medida em que grandes corporações midiáticas continuam reproduzindo imagens produzidas por esses grupos porque violência vende jornal e eleva a audiência dos noticiários.

Em termos de radicalização, Shahid acredita que tem muita gente lucrando com esse mercado e vendendo produtos que são ilusórios, como por exemplo, modelos que poderiam ajudar a identificar os sinais de radicalização.

\section{Shahid}

"Dizem pra gente que, por exemplo, um dos sinais poderia ser como alguém indo para a escola. Antes das férias de verão, o menino nunca teve barba. Depois das férias, ele voltou com uma barba grande. E um dia ele pergunta ao professor: 'Eu quero orar, quero um quarto para orar'. 'Mas você nunca pediu isso antes'. Aconteceu. Está acontecendo no Reino Unido: os professores encaminham esses alunos para o PREVENT porque eles percebem que essas pessoas estão se radicalizando. É assim que as pessoas entendem os sinais da radicalização. Realmente e verdadeiramente não há um modo definitivo de entender quando alguém se radicalizou. Porque eles não colocam um crachá na cabeça 'eu me radicalizei', eles podem ser perfeitamente normais, eles podem estar trabalhando com você, indo para a faculdade com você e nada realmente mudar, mas por dentro, eles estão mudando"

Nesse momento Shahid revela a dificuldade de resolver um problema que não é puramente ideológico. De acordo com Borum (2013), vários fatores podem levar à radicalização e cada um deles pode ser influenciado por vários outros elementos.

\section{Shahid}

"Muitos desses jovens estão desiludidos, muitos desses jovens sentem que não pertencem à sociedade onde vivem, que não têm oportunidades, enfrentam racismo, enfrentam discriminação, enfrentam a Islamofobia. Eles podem vir de famílias disfuncionais, podem ter problemas mentais, podem estar deprimidos, podem estar divorciados ou longe da namorada, ou podem estar envolvidos com drogas. Estes são todos os diferentes fatores que poderiam estar envolvidos. É por isso que eles são tão fáceis de serem pegos. É por isso que quando você conversa com muitas pessoas que foram à Síria, voltaram, deixaram grupos como o ISIS e perguntam 'por que você foi embora?', 'O que nos foi dito não é o que vimos. Não há nada islâmico no que eles fazem'. Então, essa é outra questão também, que eu enfatizei muito, especialmente com o governo, que tratar igual todas as pessoas que voltam da Síria, tratá-las da mesma forma não é correto, porque ninguém vai à Síria para lutar. Uma vez, um jovem havia sido foi levado para a Síria para se juntar a um dos grupos de lá e eu o trouxe de volta. Demorou um ano de conversas. Eu dei a ele os dois lados da 
história e contei a ele. E mesmo agora, quando o vejo, ele diz "obrigado, irmão". Eu teria estragado tudo. Muitas pessoas foram embora e foram para o lado errado e não podem sair. Existem pessoas na Síria que estão nesse momento confinadas em prisões, dentro das prisões do ISIS, basicamente percebendo que o ISIS não tem nada a ver com o Islã. Eles não são quem dizem que são, mas elas não podem fugir. Existem muitas pessoas por aí. Eu ouço histórias o tempo todo"

Shahid passou cinco anos na prisão e recentemente passou a ter uma posição mais ativa na prevenção da radicalização, tentando trazer jovens que estão na Síria e evitando que mais gente seja recrutada por grupos extremistas como o ISIS.

\section{Shahid}

"Fui libertado em 2003 e desde 2003 vivo um novo capítulo na minha vida. Voltei e foi depois do 11 de setembro. Então, obviamente, o mundo todo mudou. Família e amigos estavam meio apreensivos de falar comigo porque eu tinha um estigma de que agora sou um terrorista. Psicologicamente, eu estava em um lugar escuro porque eu passava a maior parte do tempo na prisão, em confinamento ou eu estava isolado de outros prisioneiros. Eu tive muito tempo para pensar e contemplar. Financeiramente, eu estava quebrado e ninguém vai me dar um emprego. Então, eu tive que me reconstruir novamente. Reconstruir a minha vida. Há cerca de seis anos, com o surgimento do ISIS, comecei a ficar um pouco mais vocal porque percebi que era algo muito perigoso. Se você tirar a palavra ISIS, o que fica é essa ideologia do 'nosso jeito', que 'estamos certos e todo mundo está errado'. Essa ideologia que chamamos de takfir, quando anunciamos que outro muçulmano é descrente, porque ele não concorda com o seu entendimento particular de religião - que não é aceitável. Isso sempre esteve por aí, talvez não organizado como o que vimos com o ISIS, mas esse tipo de mentalidade existe há muito tempo. Eu entendo a mentalidade deles, eu entendo a paixão deles, eu entendo os argumentos deles, o interesse deles, e eu entendo como é emotivo e o tipo de palavras que eles usam e como eles podem pegar pessoas que não entendem sua religião. Eu comecei a me tornar mais vocal, comecei a sair mais, quando as pessoas perceberam que eu estava de volta à cena novamente, começaram a me convidar para dar palestras, ir à mesquita ou aos centros comunitários. Agora, chegou a um estágio em que faço esse trabalho em tempo integral. Eu viajo pelo país, vou para o exterior, trabalho com várias organizações diferentes. Sou independente, mas trabalho com pessoas diferentes. Trabalho com a polícia, o grupo antiterrorismo, com o governo, alguns projetos do Home Office, projetos comunitários, projetos privados, meus próprios projetos. Tanto faz. Estou fazendo muito trabalho no exterior e estou aconselhando os governos sobre como desenvolver estratégias para resolver esse tipo de coisa. Estratégias lidando com formadores como eu, como envolver mais pessoas como eu nisso, envolvê-las porque elas têm uma visão única e podem ser bastante influentes, impedindo as pessoas de se juntarem a grupos extremistas como o ISIS e coisas assim"

Perguntado sobre o que o Shahid de hoje aconselharia ao Shahid de anos atrás, ele não hesitou em destacar a importância da educação, deixando claro que não adianta apenas reforçar esquemas de monitoramento e vigilância nas escolas, hospitais e vias publicas. Quando o assunto é radicalização, informação pode salvar vidas. Quanto ao momento que passou fora do Reino Unido, lutando com mujahideens, Shahid não expressa arrependimento. 


\section{Shahid}

"Eu aconselharia a não ser tão desobediente quando criança. Eu também me aconselharia a estudar e, definitivamente, a aprender uma habilidade. Olhando para trás, foi um grande erro que cometi. Isso me causou muitos problemas. Além disso, eu não me arrependo de verdade. Eu não me arrependo de ir à Bósnia, eu não me arrependo de fazer as coisas que fiz. Sim, lamento a ideologia extremista que tive por um curto período de tempo. Olhando para trás agora vejo que foi um erro. Eu estava equivocado. Eu não acredito que qualquer coisa que eu fizesse era ruim e errada. Eu não matei pessoas inocentes, nunca defendi isso, nunca estive envolvido nisso. Então, não tenho nada do que me envergonhar nesse sentido"

\section{Bibliografia:}

Borum, R. (2011) Radicalization into Violent Extremism I: A review of Social Sciences Theories. Journal of Strategic Security, 4(4), 7-36. Disponível em https://search.proquest. com/docview/1751143797?accountid=14987\&rfr_id=info\%3Axri\%2Fsid\%3Aprimo [Acessado 4 Maio 2018]

Esposito, J. (2002). Unholy war: terror in the name of Islam. Oxford: Oxford University Press.

Hegghammer, T. (2006). Global jihadism after the Iraq war. The Middle East Journal, 60(1), 11-32. Disponível em http://docserver.ingentaconnect.com.ezproxy.westminster.ac.uk/ deliver/connect/mei/00263141/v60n1/s2.pdf?expires $=1525459747 \&$ id=0000\&title$\mathrm{id}=72010011 \&$ checksum=BB29833D6CBBC9A5FE2F08A52CCE5533 [Acessado 4 Maio 2018]

Kepel, G. (2011). The Origins and Development of the Jihadist Movement: from Anti-communist to Terrorism em F. Volpi (ed.) Political Islam: A critical reader. London: Routledge. 255-270.

Neumann, P. (2016). Radicalized: new jihadists and the threat to the West. London: I.B. Tauris.

Wiktorowicz, Q. (2011). A genealogy of Radical Islam em F. Volpi (ed.) Political Islam: A critical reader. London: Routledge.

Wilkinson, P. (2001). Terrorism versus Democracy: the liberal state response. London: Frank Cass.

Texto recebido em: 10 de Maio de 2018 Aprovado para publicação em: 18 de Junho de 2018 